\title{
AGE-RELATED CHANGES IN THE CATECHOLAMINERGIC NEURONS OF THE MESOPONTINE TEGMENTUM IN THE RAT
}

\author{
Dimitar E. Itzev ${ }^{1}$, Wladimir A. Ovtscharoff ${ }^{2}$ Enrico Marani, Kamen G. Usunoff, ${ }^{3}, 2$ \\ ${ }^{1}$ Institute of Neurobiology, Bulgarian Academy of Sciences, Sofia, Bulgaria; ${ }^{2}$ Department of Anatomy and \\ Histology, Medical University, Sofia, Bulgaria; ${ }^{3}$ Department of Biomedical Signals and Systems, Biomedi- \\ cal Technology Institute, Twente University, Enshede, The Netherlands
}

Immunohistochemistry and computer assisted image analysis were used to examine the age-related changes in tyrosine hydroxylase- (TH-) immunoreactivity in substantia nigra (SN), ventral tegmental area (VTA), locus ceruleus (LC) and dopamine-betahyroxylase- (DBH-) immunoreactivity in LC and subceruleus nuclei of the rat. The findings in 3-month-old rats were compared with 28-month-old rats. In SN TH-positive neurons were concentrated in pars compacta and to a lesser extent - in pars lateralis. In VTA the TH-positive neurons were present over the entire area. In LC the immunoreactive perikarya were densely arranged and superimposed, but in subceruleus nuclei they were less numerous and individual cells were clearly discernible. The DBHimmunoreaction distinctly demonstrated the noradrenergic LC and subceruleus neurons. The results indicate of only subtle signs of cell loss in the dopaminergic neuronal population of SN and VTA, whilst the cell loss of the noradrenergic neurons in LC and subceruleus nuclei is evident. On the other hand, considerable age-related dendritic alterations were observed in all catecholaminergic nuclei. Cross-sectional area and optical density (OD) of the TH-immunoreactive neurons in SN, VTA and LC, and of the DBH-immunoreactive neurons in LC and subceruleus nuclei were investigated. In aging the cross-sectional area decreased statistically and $O D$ of the neurons in SN decreased with 13\%. In VTA the cross-sectional area did not change its dimensions, while the OD increased with 19\%. In LC and subceruleus nuclei the cross-sectional area decreased with $36 \%$ and the OD of the neurons decreased with 16\%. In conclusion, the most resistant to age-related changes catecholaminergic region in the rat is the $V T A$, followed by the pars compacta of SN. Rodent LC is a very vulnerable region. Biomed Rev 2007; 18: 45-58.

Key words: substantia nigra, ventral tegmental area, locus ceruleus, tyrosine hydroxylase, dopamine-beta-hydroxylase

Received 30 October 2007, accepted 6 December 2007.

Corresponence and reprint requests to Dr. Kamen G. Usunoff, Department of Anatomy and Histology, Medical Faculty, Medical University, 1 Sv G. Sofiiski Str., 1431 Sofia, Bulgaria. Tel. +359(2)9172 525, E-mail: uzunoff@medfac.acad.bg 


\section{INTRODUCTION}

Aging is often accompanied by behavioral changes, such as impaired memory, alterations in motor coordination, reduced sensory acuity, sleep pattern changes. Such alterations correspond to neurodegenerative disorders in man occurring with aging, such as Parkinson's disease and Alzheimer's disease. In the catecholaminergic nuclei of the brainstem several cellular markers have been characterized such as changes in the neuromelanin content, lipofuscin accumulation, appearance of neurofibrillary tangles, Lewy and Marinesco bodies, reduced neuronal density (necrotic and/or apoptotic cell loss), changes in neuronal arborization, increased populations of glial cells, as well as more recently described diverse neurochemical factors, associated with normal aging and neurodegenerative diseases (neurotransmitter changes, tau protein, alpha-synuclein, iron, free radicals, calcium-binding proteins, neurotrophic factors). These classic and recent markers have been discussed in numerous articles and reviews (1-30); for comprehensive reviews see (31-35).

Substantia nigra (SN) and ventral tegmental area (VTA) contain the major dopaminergic neuronal groups in the brainstem and are reliably demonstrated by immunoreaction for the enzyme tyrosine hydroxylase (TH). The TH is a rate-limiting enzyme for dopamine synthesis, therefore, immunohistochemistry for TH can be used as a marker of dopaminergic neuronal alterations in these regions, especially in the brains of lower mammals that lack neuromelanin in the catecholaminergic neurons (reviewed in 34). Immunohistochemical investigations of the TH-immunoreactive neurons during aging in humans and different animal species have so far yielded controversial results. There are data on age-related changes of density of the TH-immunoreactive neurons $(11,36-43)$, changes of TH-activity $(29,44-46)$, changes of TH mRNA activity $(38,47)$, and changes in the dopamine content of the cells $(37,44,48-52)$.

The LC and subceruleus nuclei (dorsal and ventral) attracted much attention in the recent decades and there is a considerable body of literature, reporting a decrease of the neuron number with advancing age (4,53-56). In most studies neuromelanin was used as a marker of noradrenergic neurons, and some studies have additionally used immunohistochemical staining with antibody against TH (56-59), or against dopamine-betahydroxylase (DBH) (58-60).

We investigated qualitatively and quantitatively the changes in the morphological appearance, cross-sectional area and optical density (OD) of the TH-immunoreactive neurons in $\mathrm{SN}$, VTA, LC, and of DBH-immunoreactive neurons in LC and subceruleus nuclei during aging in rats. A preliminary report was presented (61).

We analyzed young (3-months-old) and aged (28-months-old) Wistar rats by staining their brains under standard immunohistochemical protocols (62) with antibodies directed against $\mathrm{TH}$ and DBH. For reconstruction of the investigated nuclei tissue sections were arranged according to the stereotaxic atlas of Paxinos and Watson (63). Subsequent image analysis was performed qualitatively and quantitatively by measuring and comparison of cross-sectional area and optical density (OD) of positive neurons. Quantitative analysis was performed on an image analysis system consisting of Jenaval photomicroscope, Hitachi videocamera, IBM computer and appropriate software. Every positive neuron was measured and the calculation was made as follows: the mean value of the area surface of the neurons in the young animals was accepted as $100 \%$. The OD of the cell bodies was expressed on an arbitrary scale ranging from 0 to 256 ( 0 - absolutely black, 256 - the OD of the adjacent glass outside of the section). The results obtained were statistically processed using Student's t-test and mean \pm standard error of the area surface and OD were calculated. Statistical significance was accepted at $\mathrm{p}<0.05$.

\section{Qualitative data}

In the $\mathrm{SN}$ of young (control) rats, the TH-immunoreactive neurons were densely arranged in pars compacta (Fig. 1a) and a lower number was found in pars lateralis, while in pars reticulata only a few immunopositive cells were observed. In the VTA the TH-immunoreactive cells were distributed over the entire area, and were condensed in the rostral linear nucleus, the paranigral nucleus, and especially - in the interfascicular nucleus (Fig. 2a, c). In the LC the TH- and DBH-immunoreactive neurons were extremely densely arranged (Fig. 3a, 4a), whilst in the dorsal and ventral subceruleus nuclei the cells were more loosely arranged and the individual immunopositive neurons were clearly outlined with Golgi silver impregnation-like quality, especially by the DBH-immunolabeling (Fig. 4a, 5a, b).

The immunohistochemical reaction for TH and DBH revealed that the reaction product was brownish, homogenous and filled the entire perikaryon of the labeled neurons. As a rule, it extended in the dendrites and axons of the catecholaminergic neurons. No reaction product was found in the neuronal nuclei.

In SN and VTA of young animals the TH-immunoreactive neurons displayed different size and shape. In SN pars com- 

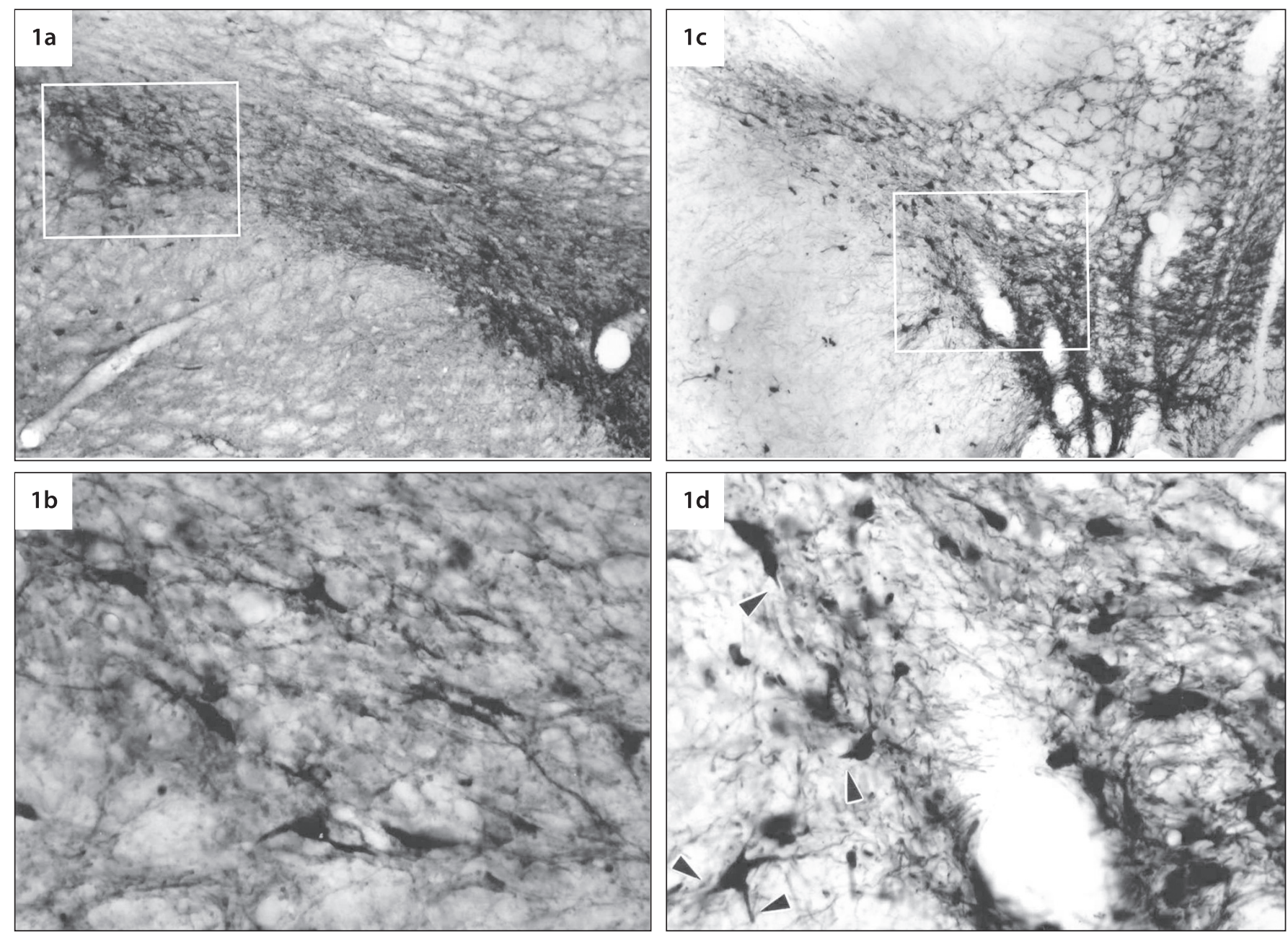

Figure. 1. SN pars compacta. (a) Demonstration of TH-immunoreactivity in 3-month-old rat. Medial is to the right. Densely arranged labeled neurons in the medial and central portions of pars compacta; in pars reticulata (to the left) only few scattered labeled neurons are seen, $x$ 100. (b) Detail from (a). Most of the neurons are elongated, oriented in medio-lateral direction. The neuropil contains a dense plexus of labeled processes, $x$ 400. (c) Demonstration of TH-immunoreactivity in 28-month-old rat. Medial is to the right. Medial portion of pars compacta, close to the dorso-ventrally oriented axons of the oculomotor nerve, $x$ 100. (d) Detail from (c). Some neurons display distorted perikarya. Many dendrites are amputated and the dendritic stumps are indicated by arrow heads, $x 400$.

pacta many labeled neurons were elongated, with the long axis oriented medio-laterally (Fig. 1b). The dendrites arose usually from the two perikaryal poles but many neurons in the ventral part of pars compacta emitted also ventrally oriented dendrites that penetrated the pars reticulata. The neuropil of pars compacta exhibited a dense plexus of immunolabeled processes. In the VTA multipolar neurons predominated. Especially in regions with dense neuronal aggregations, like the rostral linear nucleus (Fig. 2b), the neuropil contained a dense network of thin dendrites and axons.

The histological changes in the TH-immunoreactive neu- ronal populations of SN (Fig. 1c, d), and VTA (Fig. 2c, d) in aged animals were relatively mild. In SN pars compacta only subtle signs of cell loss were encountered: $1.5-3.5 \%$ compared to the young animals. In SN many elongated neurons appeared even more "slender", nearly fusiform, and some perikarya were distorted. Amputated dendrites, with only dendritic stumps left, were a common finding and thin secondary dendrites were few (Fig. 1d). The density of neuropil labeling diminished. In VTA (Fig. 2c, d) a limited number of the perikarya appeared shrunken and darker, most evident in the elongated neurons of nucleus paranigralis (Fig. 2d). The loss of dendrites was com- 

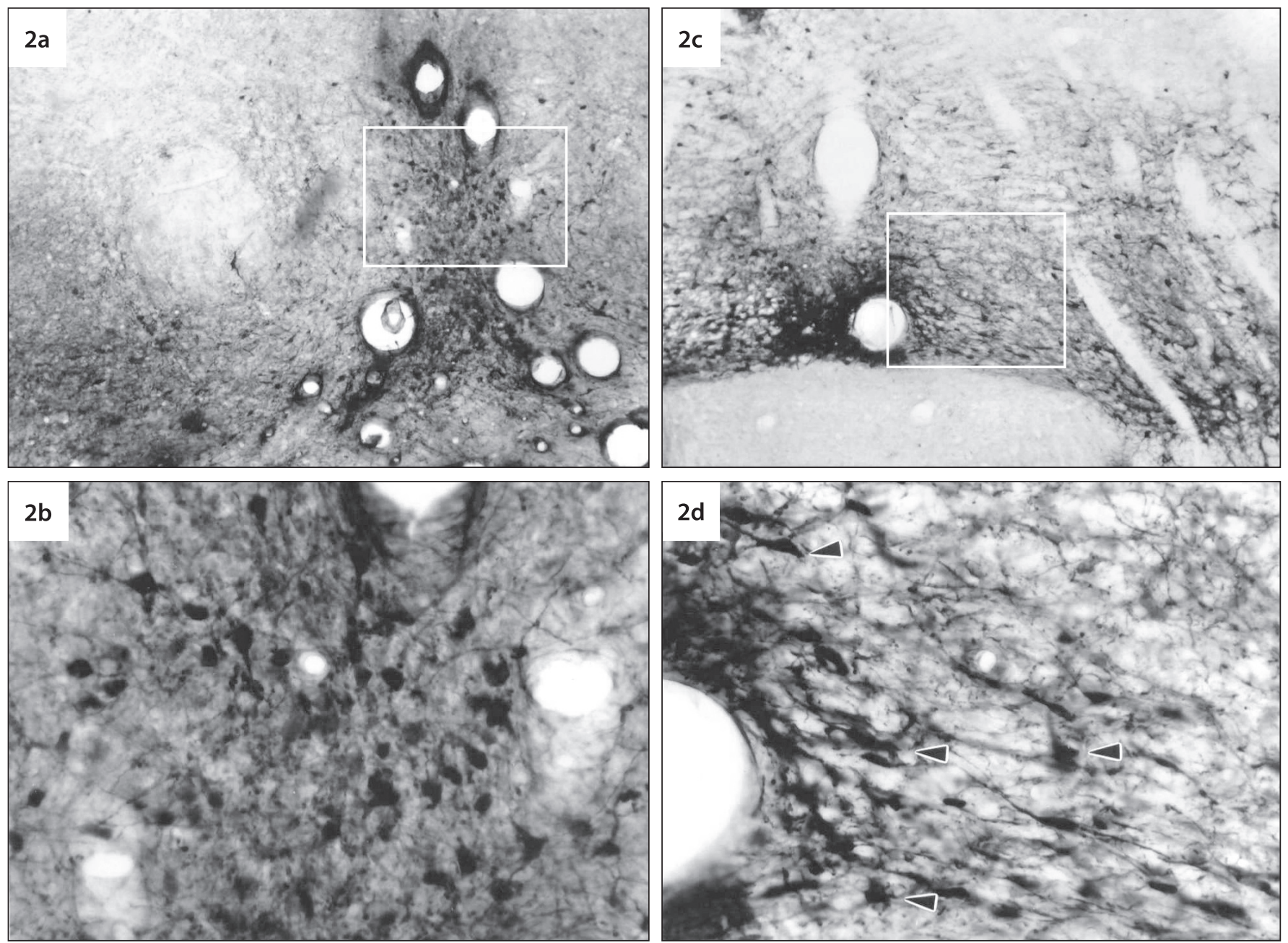

Figure 2. VTA. (a) TH-immunoreactivity in neurons of 3-month-old rat. The abundant blood vessels indicate the midline. Between them the densely arranged immunoreactive neurons of the rostral linear nucleus are seen, $x 100$. (b) Detail from (a). The neurons in the rostral linear nucleus are slightly smaller than the TH-immunopositive cells of pars compacta. Most of the perikarya are rounded-multipolar. The neuropil contains a dense plexus of thin, tortuous and varicose dendrites, $x 400$. (c) TH-immunoreactivity in 28-month-old rat. The dense neuronal aggregation around the blood vessel is the midline, unpaired interfascicular nucleus. Lateral to it, and medial to the axons of the oculomotor nerve are the more loosely arranged neurons of the paranigral nucleus, $x$ 100. (d) Detail from (c). Lateral border of the interfascicular nucleus and medial portion of the paranigral nucleus. Some neurons retain their dendrites but many cells display amputated dendrites close to the perikarya (arrow heads), $x 400$.

mon, and from certain perikarya only very short and thickened dendritic stumps arose (Fig. 2d).

The immunostaining for TH and DBH in LC and dorsal subceruleus nucleus in young animals (Fig. 3a, b, 4a) exhibited identical results. LC was sharply outlined from the pale adjacent regions. Within the nucleus the neurons were superimposed and details of the individual cells were discriminated with difficulty. Such were clearly visible only in the periphery of LC. Very characteristic for the both immunostainings was a rich dendritic radiation that penetrated the surrounding regions. The dorsal subceruleus nucleus, nominated as "subceruleus nucleus, alpha part" by Paxinos and Watson (63), contained a less dense aggregation of labeled neurons, so that the cellular details were discernible. The neuropil contained numerous labeled processes, most of them - dorsoventrally oriented dendrites (Fig. 4a). The DBH immunostaining of the ventral subceruleus nucleus in young animals (Fig. 5a, b) demonstrated large, multipolar, intensively labeled neurons with 

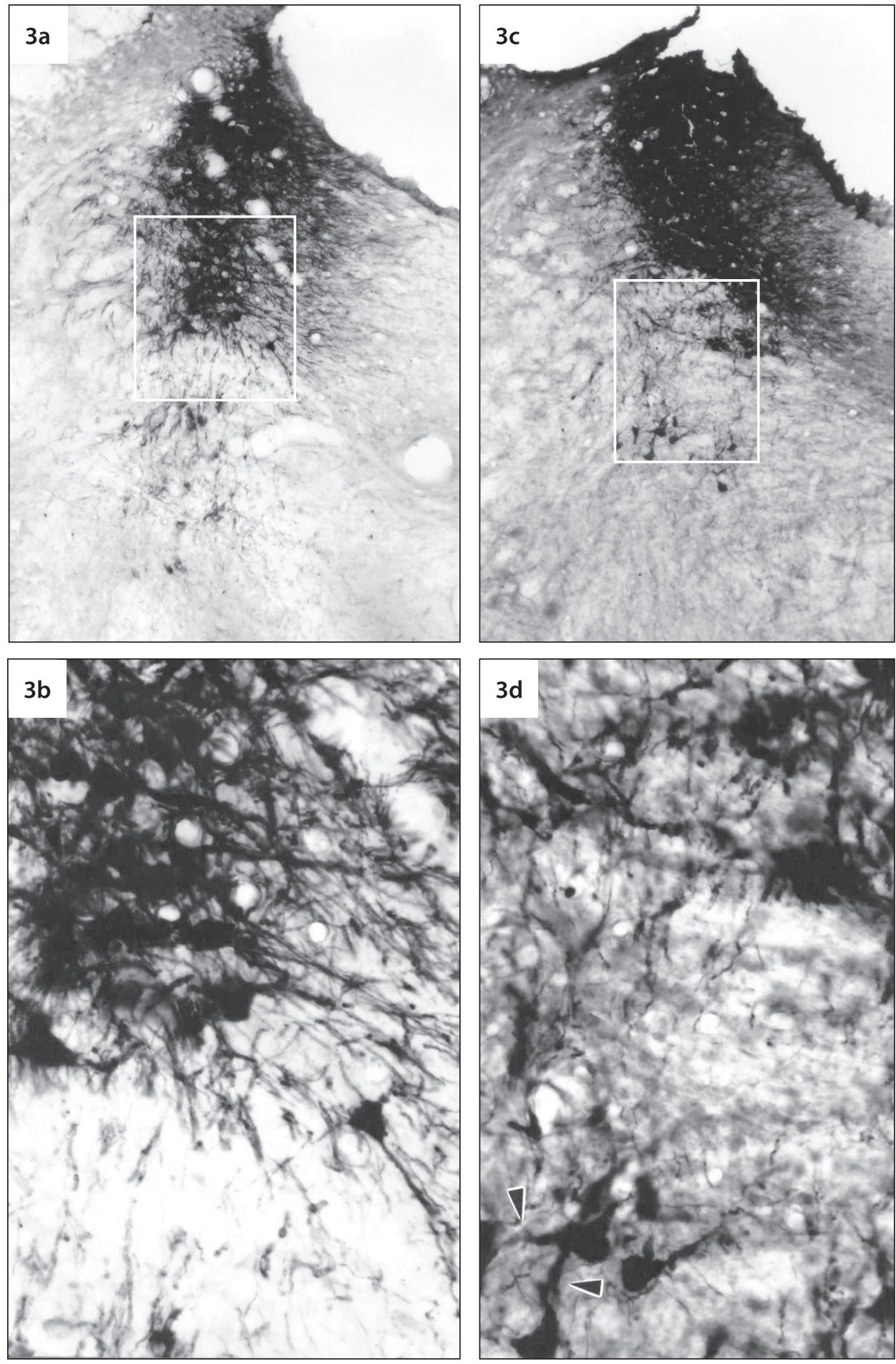

Figure 3. LC and dorsal subceruleus nucleus. Medial is to the right. (a) TH-immunoreactivity in a young rat. The dense aggregation of the LC noradrenergic neurons is sharply outlined against the pale background. Numerous long dendrites spread over adjacent territories. Ventral to the LC are located the more loosely arranged neurons of the dorsal subceruleus nucleus, $x$ 100. (b) Detail from (a). Ventral portion of LC. Due to the superimposition of the labeled neurons cellular details might be encountered only in the most peripheral cells. The scant neuropil contains numerous capillaries, $x$ 400. (c) TH-immunoreactivity in an old rat. The "dendritic fan", surrounding the LC is clearly reduced, x 100. (d) Detail from (c). Border zone between LC and the dorsal subceruleus nucleus. The perikarya of the latter emit short, stumped and thickened dendrites (arrowheads), $x 400$. 

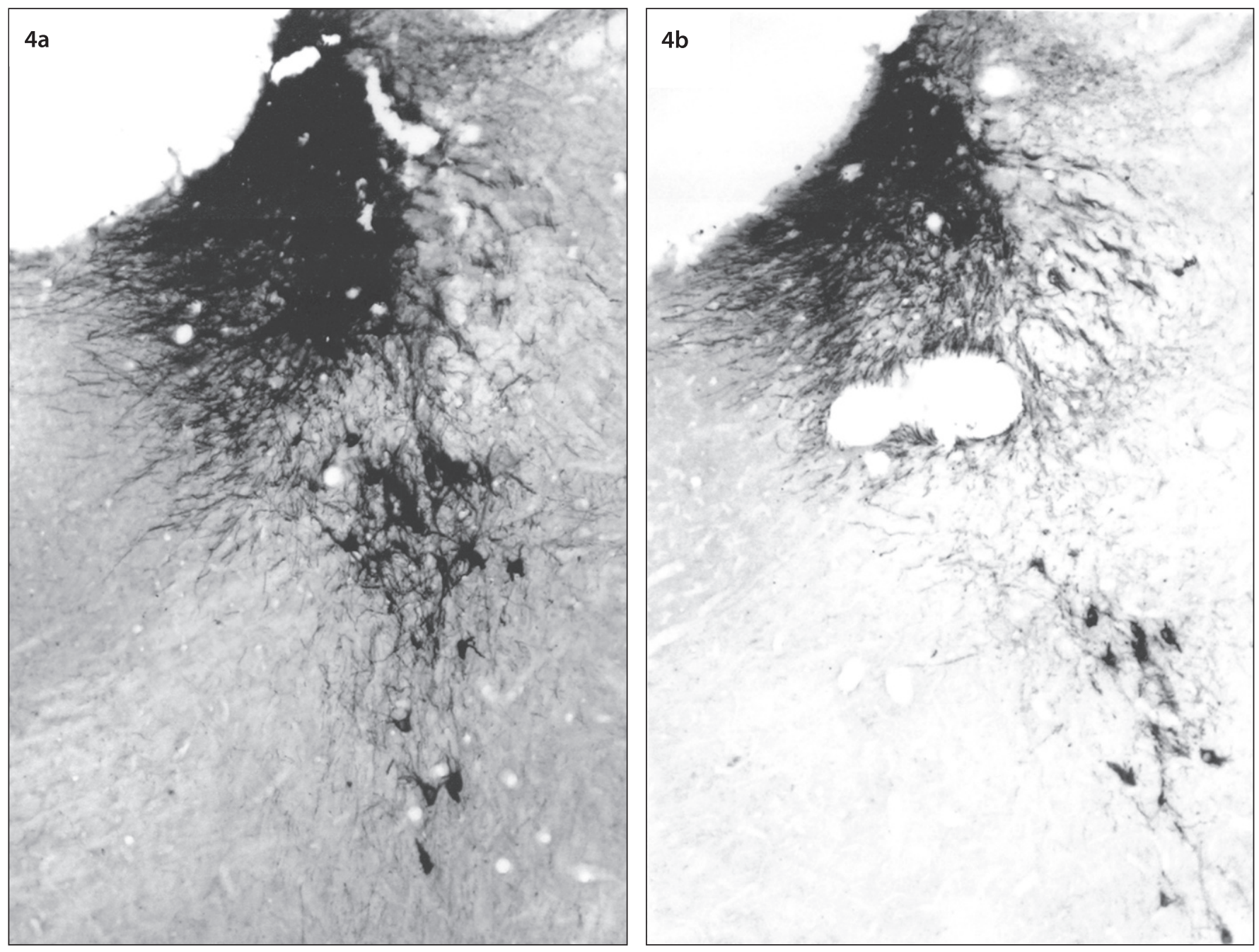

Figure 4. LC and dorsal subceruleus nucleus. Medial is to the left. Comparison of DBH-immunoreactivity of 3-month-old rat (a) and 28 month-old-rat (b), x100. The finding is identical with the TH-immunoreactivity shown in Figure 3. In aged rats the neuronal cell loss is especially evident in the ventral and lateral portions of the LC as well as in the dorsal subceruleus nucleus.

robust primary dendritic trunks and long secondary dendrites. In the neuropil numerous thin, varicose axons were seen (Fig. $5 b)$.

The histological changes in the TH- and DBH-immunoreactive populations of the $\mathrm{LC}$ and subceruleus nuclei in aged animals were more pronounced than by the SN and VTA. First, in all three structures the cell loss was immediately evident (Fig. $3 \mathrm{c}, 4 \mathrm{~b}, 5 \mathrm{c})$. In LC the cell loss appeared to be most pronounced in the ventral and lateral portions of the nucleus. The number of immunoreactive dendrites, radiating in adjacent regions, was strongly reduced (Fig. 3c, 4b). In the dorsal subceruleus nucleus, especially in the Paxinos' "alpha part", the cell loss was drastic (compare Fig. 4a and 4b). Heavily deteriorated was also the ventral subceruleus nucleus (Fig. 5c, d). In addition to the prominent cell loss, the DBH-immunoreactive neurons were heavily altered. The perikarya were clearly atrophic, and not rarely - paler than the neurons in young animals. The rich dendritic arborization, observed by 3 -month-old animals, was strongly reduced and represented pale, scarcely branched stem dendrites. The amputated dendrites were a common finding, and some of the dendritic stumps were crudely thickened. The fine, varicose axons practically disappeared (Fig. 5).

\section{Quantitative analysis}

The morphometric study indicates that the cross-sectional areas of the positive neurons in SN decreased significantly in aging (Fig. 6a), from $1157 \pm 25 \mathrm{v} / \mathrm{s} 829 \pm 15 \mu \mathrm{m}^{2}(\mathrm{p}<0.001)$. The cross-sectional area decreased with $28 \%$. In the same time, the 

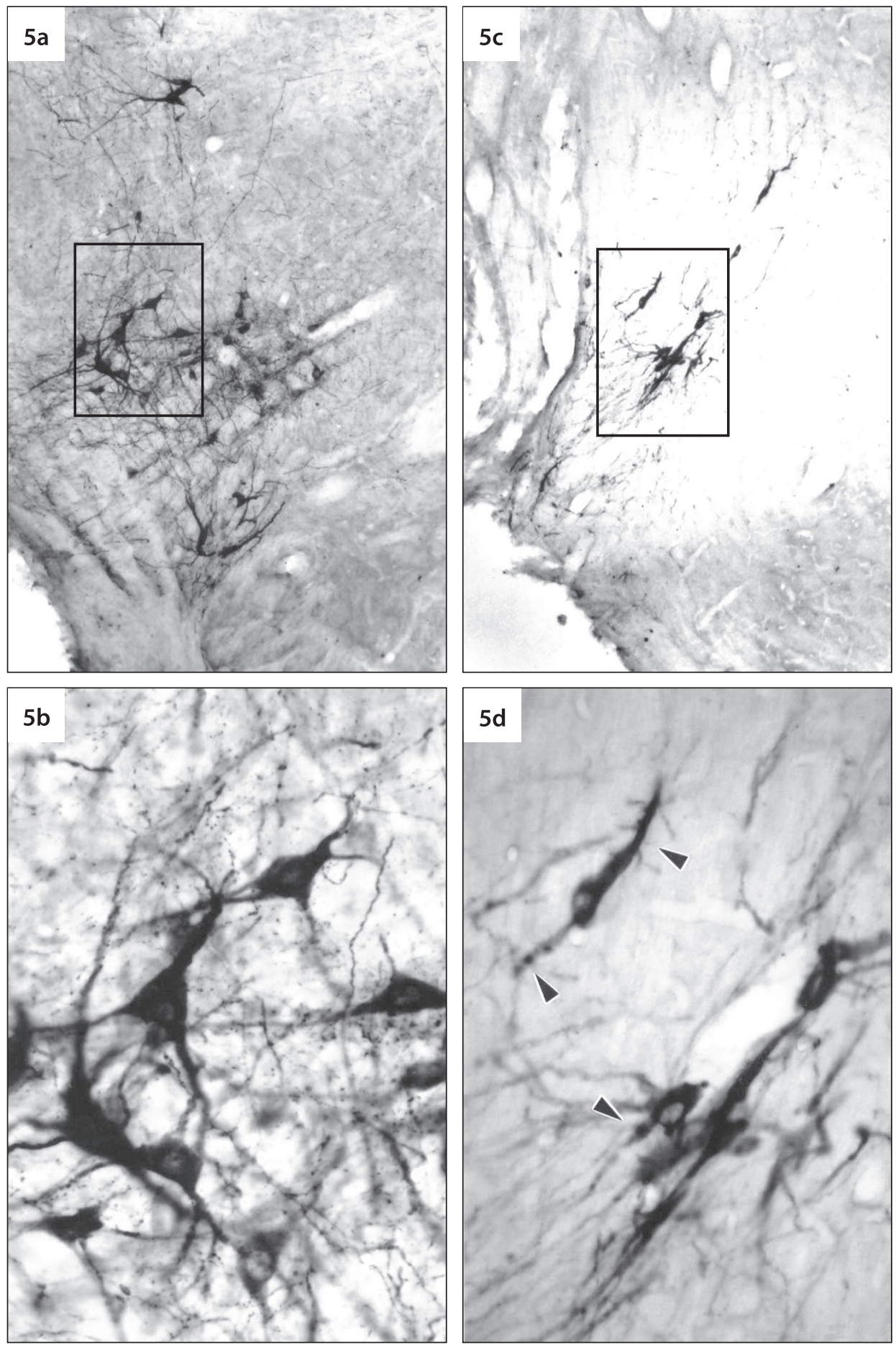

Figure 5. Ventral subceruleus nucleus. Medial is to the right. This is the most ventral part of the subceruleus region, almost reaching the brain surface, often designated as the noradrenergic A5 group of Dahlstrom and Fuxe. (a) DBH-immunoreactivity in a 3-month-old rat. The robust labeled neurons are well discerned also at small magnification in the moderately dense neuronal aggregation, x 100. (b) Detail from (a). The strong immunostaining resembles a Golgi silver impregnation. Often the perikarya emit a short, thick dendritic trunk that gives rise to more slender secondary dendrites. In the neuropil a network of thin, varicose axons is seen, $x$ 400. (c) DBH-immunoreactivity in 28-months-old rat. The drastic cell loss is evident at a first glance, $x$ 100. (d) Detail from (c). The immunolabeled nerve cell bodies are smaller, often - paler. The dendrites are both amputated and thickened (arrow heads). The thin, varicose axons disappear, $x 400$. 

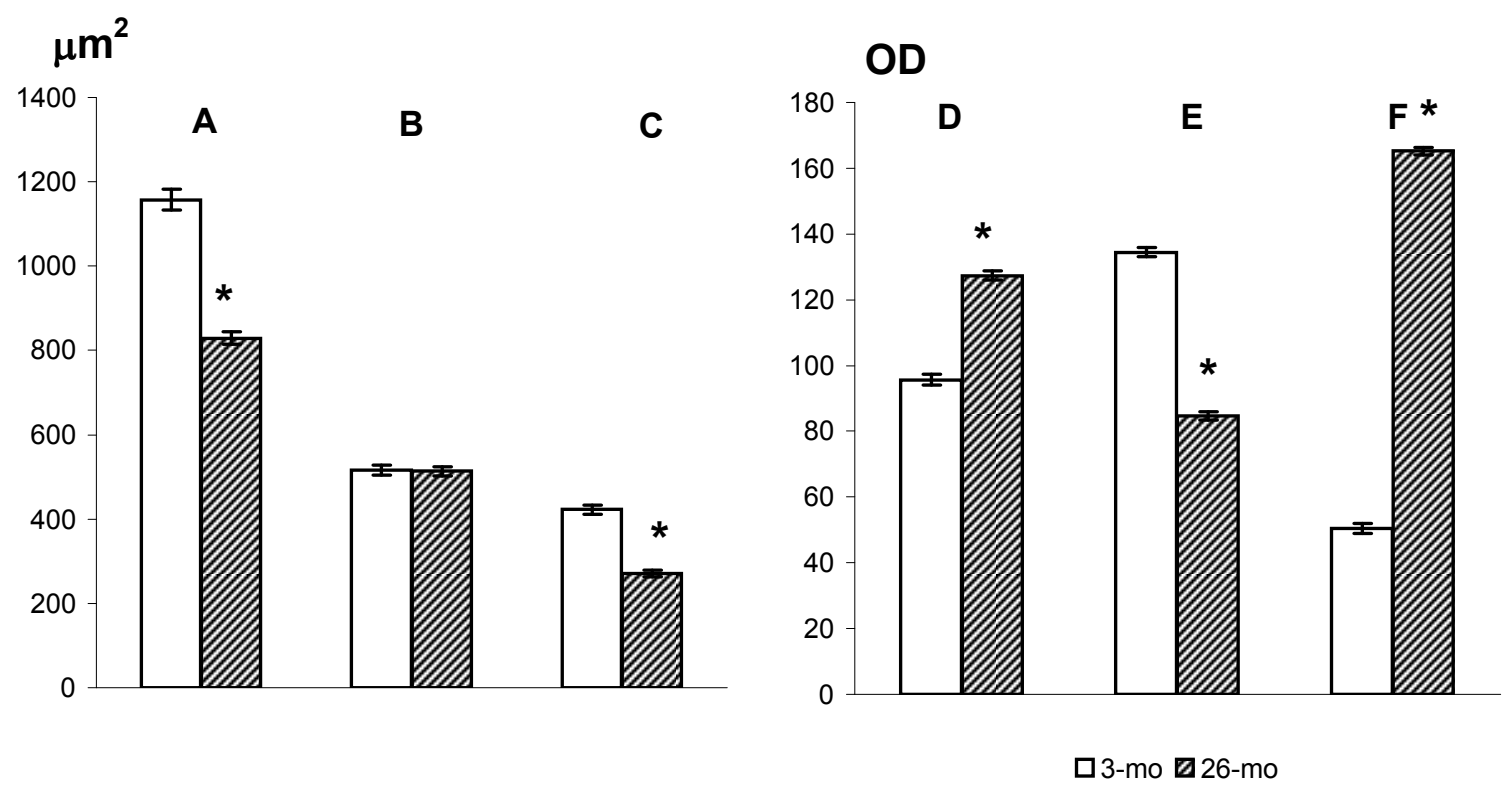

Figure 6. Diagram showing the aging changes in cross-sectional area in $\mu^{2}$ of positive neurons in $S N$ (a) and VTA (b) and OD in arbitrary units of TH-immunopositive neurons in $S N(d)$, and VTA (e). (c) Changes in cross-sectional area and (f) staining intensity of DBH-immunoreactive neurons in subceruleus nuclei $\left({ }^{*} p<0.001\right)$.

neurons in VTA (Fig. 6b) did not changed their dimensions during aging, $516 \pm 12$ versus $513 \pm 11 \mu \mathrm{m}^{2}$ ( $\left.\mathrm{p}>0.05\right)$. OD measurements of the TH-positive perikarya indicated that in $\mathrm{SN}$ OD decreased significantly with $12 \%$ (Fig. 6d), from $95 \pm 1.7$ to $127 \pm 1.4(\mathrm{p}<0.001)$. In VTA the OD increased significantly in aging (Fig. 6e), from $134 \pm 1.4$ to $84 \pm 1.2$ ( $p<0.001$ ). The OD increased with $19 \%$. The morphometric study demonstrated that the cross-sectional area of the DBH-positive neurons in LC and subceruleus nuclei (Fig. 6c) decreased significantly with $36 \%$ in aging from $423 \pm 11.1$ in 3 -month-old rats to $271 \pm 7.5$ sq $\mu \mathrm{m}(\mathrm{p}<0.001)$ in old rats. OD of the DBH-immunoreactive neurons in the subceruleus nuclei (Fig. 6f) of the 3-month-old rats was $51 \pm 1.5(\mathrm{p}<0.001)$ but in aged rats it decreased with $42 \%$ to $165 \pm 1.2(\mathrm{p}<0.001, \mathrm{n}=100)$.

\section{Comparison of our results with the data available}

The most characteristic neuropathologic feature of the Parkinson's disease is the both prominent and selective neuronal cell loss of the pigmented (dopaminergic) neurons of the SN pars compacta $(1,9,11,17,32-34,64,65)$. The observations on the age alterations of $\mathrm{SN}$ in humans and experimental animals are less straightforward. Mann and Yates $(2,3)$ demonstrated that a gradual decline takes place from 60 to 90 years in all neuromelanin-containing nuclei, and especially - in SN. The number of pigmented SN neurons $(2,3,9,20,66,67)$ was re- ported to progressively decrease. In 36 control cases ranged in age from 21 to 91 years, Fearnley and Lees (9) reported a decline of $4.7 \%$ per decade, and the total decrease reached $33 \%$. There was a significant sparing of the ventrolateral and ventrointermediate neuronal groups in SN pars compacta$15 \%$ cell loss. Interestingly, the same neuronal groups are most severely affected by idiopathic Parkinson's disease $(1,9,32,65)$. Faraldi et al (15) supported the hypothesis that the overload of neuromelanin in advanced aging is neurotoxic and contributes to the cell loss in SN. Bannon and Whitty (40) reported up to $75 \%$ loss of the dopamine transporter mRNA in older persons, but also noticed that the TH expression in the dopaminergic neurons was less affected. An age-related reduction in the number of SN dopamine transporter-immunoreactive neurons was established also by Ma et al (67). Chu et al (68) reported that in the human SN the number of both Nurr1- and THimmunoreactive neurons was mildly diminished already at middle age, and severely reduced in aged cases. Cabello et al (20) stated that the cell loss in the aged human SN may be compensated by hypertrophy. In contrast to the data discussed above, Kubis et al (41) provided unexpected results. They examined the human $\mathrm{TH}$-immunostained neuronal population in SN, VTA and LC in 21 control subjects who died at ages 44-110 years. They found no statistically significant cell loss of TH-immunopositive neurons. 
The animal studies also provided somewhat diverse results. Irwin et al (39) examined young, intermediate-aged and old squirrel monkeys. Contrary to the obvious functional and neurochemical age-related changes (30-70\% loss of dopamine in the neostriatum), the number of TH-immunoreactive cells did not significantly differ among the three age groups. Pakkenberg et al (52) examined the number of pigmented and nonpigmented SN neurons in young and old monkeys. They established that the total number of pigmented neurons was about eight times higher in old animals compared with young ones but the cell loss appeared to be minimal. Siddiqi and Peters (18) and Siddiqi et al (69) reported a SN and VTA cell loss in old rhesus monkey but, interestingly, they stated that the aging affects more significantly the small GABAergic interneurons than the large dopaminergic projection neurons. According to Gerhardt et al (70), there are only modest (15-20\%) declines of SN pars compacta TH-positive cells in the course of normal aging. McCormack et al. (43) found no significant differences in the SN cell number in young, middle-aged and old squirrel monkeys, but pointed out also that there is a decrease of TH-immunoreactivity, paralleled with an increase of the neuromelanin content. Collier et al (46) reported that in rhesus monkeys the age-associated morphological changes include decline in the density of TH-positive fibers in striatum, decreased SN soma size, and optical density of TH, but no significant loss of neurons. The differences in the normal aging and neuropathology in the different neuronal groups in the human SN pars compacta is established (9; reviewed in $34)$ but such a delineation was reported in monkeys only very recently. Kanaan et al (29) investigated young, middle-aged and old rhesus monkeys. They found out that the TH-positive neuron numbers were inversely correlated with advancing age specifically in the ventral tier of the SN pars compacta, not in the dorsal tier or in the VTA. TH intensity decreased throughout the ventral midbrain with increasing age, an effect exacerbated in the ventral tier of SN pars compacta. Uchida et al (42) established that the TH-positive neurons in SN of old dogs appear to be well preserved but they found also cytological alterations typical for the human neuropathology. Tatton et al (36) and Greenwood et al (51) investigated the SN and LC in C57B1 mice aged 8 to 104 weeks, and found that the neuronal loss was due to neuronal death rather than loss of TH-immunoreactivity. The cytoplasmic TH was increased by $63 \%$ in 104 -week-old mice in comparison to 8 -week-old animals $(51)$. McNeill et al $(48,49)$ investigated the SN in young and aged C57B1/6N Nia mice. They found a progres- sive accumulation of cytoplasmic lipofuscin granules and a markedly reduced dopamine content per cell as determined by histofluorescence. Further, McNeill and Koek (50) investigated six age groups (3-30 months aged) of the same mouse strain, and reported a small decline $(11 \%)$ in the total number of dopaminergic neurons of the SN with age, a decrease not reaching a statistical significance. Emerich et al (37) postulated that there are no reductions in number, area and length of TH-immunoreactive neurons in A8, A9 and A10 regions of 24-25-month-old rats. Schuligoi et al (38) suggested that the reduction in TH mRNA in the VTA and SN pars compacta in 33-month-old Sprague-Dawley rats is not due to a loss of TH mRNA expressing cells but due to a reduction in the hybridization signal per expressing cell. Himi et al (47) investigated the expression of mRNAs encoding the dopamine transporter and $\mathrm{TH}$ in SN of young and aged Fischer 344 rats. They found that dopamine transporter mRNA decreases by 18 months, whilst TH mRNA reduction does not occur until 24 months. In the same rat strain the dopaminergic neurons exhibited increased axonal branching between 6 and 24 months (71). De la Cruz et al (45) report a significant decrease (55\%) of TH activity in rats between 12 and 24 months of age, while others established that in old mice the number of SN dopaminergic neurons was decreased by $10 \%$ in contrast to TH-immunodensity which was $24 \pm 3 \%$ higher compared to young animals (24). Recently, Cruz-Muros et al (72) compared the nigrostriatal and mesolimbic (e.g. - the VTA fiber system ascending to limbic forebrain targets) in rats and suggested that both the nigrostriatal and the mesolimbic systems are vulnerable to aging, but in contrast to what occurs in Parkinson's disease, the mesolimbic system is more vulnerable to aging than the nigrostriatal ones.

Due to the very uneven distribuition of the TH-immunoreactive neurons in VTA, we attempted a comparison of the neuronal number of labeled cells only in SN pars compacta. The results were nearly negative (a decrease of $1.5-3.5 \%$ by the old rats). Thus, our data are even lower than reported by McNeill and Koek (50), who found a decline of $11 \%$, and declared that it does not reach a statistical significance. The observation of SN pars compacta suggested only mild atrophic changes of the TH-positive neuronal perikarya. The morphometric study, however, demonstrated that the cross sectional area of the positive neurons decreased with $28 \%$. A decreased SN soma size without a cell loss was also reported in monkeys (46). In VTA the cross sectional area did not change. Such a discrepancy between SN and VTA dopaminergic neurons was not observed by Emerich et al (37). They declared that none of 
the midbrain dopaminergic groups show area reduction of the TH-positive neurons. It is hard to explain the aging stability of the VTA neurons compared with the SN ones. Our results run counter to the data presented by Cruz-Muros et al (72), who reported findings contrary to ours - the VTA neurons are more vulnerable to aging than the $\mathrm{SN}$ cells. In the human brain the cell loss in the aged SN may be compensated by hypertrophy (20) but apparently this phenomenon is absent in the rodent SN. Our data suggest that the OD of TH-positive perikarya in $\mathrm{SN}$ decreased with $12 \%$ in aged rats. Kanaan et al (29) also found a reduction in the $\mathrm{TH}$ activity in $\mathrm{SN}$, especially prominent in the ventral tier of pars compacta in monkeys. Strangely, we found that in VTA the OD increased in old rats with $19 \%$ - another difference between the nigrostriatal and mesolimbic neuronal population in the mesencephalon. The VTA dopaminergic neurons are not only resistant to atrophic changes but also display an increased TH activity. A significant increase of the TH activity was reported also by Greenwood et al (51) but this appears to be a compensation of unusually strong cell loss, reported by these authors. Very similar results were reported by Kim et al (24).

With few exceptions $(41,73)$, the investigators agree that with advancing age there is a decrease in number of LC neurons in man $(4,34,53-56,58-60,74,75)$. The data in rodents are somewhat contradictory but probably this is also due to the different strains examined. Goldman and Coleman (76) reported that in LC of Fischer 344 rats of ages from 12 to 32 months there is no neuronal cell loss with advancing age. On the other hand, Sturrock and Rao (77) found a $47 \%$ decrease in Nissl-stained LC neurons in 31-month-old mice, compared to 6- and 15-month-old mice. Shores et al (78) found a LC cell loss in Brown-Norway rats but also reported an increase of $\mathrm{TH}$ mRNA which may potentially increase noradrenaline synthesis in the remaining neurons. Also, Tatton et al (44) counted immediately adjacent TH-immunoreacted and Nissl-stained sections through the LC in mice at different ages, and concluded that the neuronal loss was due to neuronal death rather than loss of TH immunoreactivity. The present results indicate the occurrence of a significant cell loss in the LC of aged Wistar rats, although not as dramatic as declared by Sturrock and Rao (77). The cell loss was predominantly localized in the ventral and lateral portions of the $\mathrm{LC}$, and the dendritic radiation within surrounding structures was significantly reduced. In the subceruleus nuclei the cell loss was also prominent. In two out of four cases (one of them demonstrated on Fig. 4) the "alpha part" of the dorsal nucleus subceruleus was literally erased. The cell loss in the ventral subceruleus nucleus was also massive and was accompanied by a complete degeneration of the intrinsic plexus of noradrenergic axons. We investigated the cross-sectional area and the OD mainly in the subceruleus nuclei since the superimposition of the labeled neurons in LC obscured the detailed visualization of individual neurons. According to the present results the cross-sectional area in the DBH immunoreactive neurons decreased with $36 \%$. These data were averaged. As seen in Figures $5 \mathrm{~b}$ and $5 \mathrm{~d}$, some neurons undergo even more severe atrophic changes. The OD according to the present data decreased dramatically in aging - with $42 \%$. It is not easily detectable by the observation of the neuronal perikarya but the pale appearance of the dendrites on Figure $5 \mathrm{~d}$ supports the validity of the OD measurement.

All catecholaminergic neuronal groups presently examined exhibited heavy alterations in the dendritic and axonal arborization by advanced aging. A common finding was the dendritic loss, accompanied by distorted and thickened dendritic stumps. This phenomenon appears to be common throughout the phylogenetic scale, since similar changes were reported also by Cruz-Sanchez et al (79). They applied detailed tracing of Golgi stained neurons in the SN of 20 human control brains ranging from 20 to 93 years of age. Cruz-Sanchez et al (79) encountered distorted profile of the cell body, loss of dendrites and dendritic spines, and swelling and beading of the dendritic branches mainly in the oldest group (70-93 years). Heavy dendritic alterations are also present in aging noncatecholaminergic neuronal populations producing nitric oxide: the cholinergic neurons of the pedunculopontine and laterodorsal tegmental nucleus (80), and the neurons of the dorsolateral column of the periaqueductal gray (81). Finally, von Bohlen und Halbach et al (82) reported a significant decrease in spine number of CA1 dendrites of the aged murine hippocampus that are clearly related to the memory and cognitive impairment. Thus, the obvious alterations of the dendritic tree appear to be a universal phenomenon for different neuronal populations, in different species.

\section{CONCLUSION}

There were only subtle signs of cell loss in the dopaminergic neuronal population of SN and VTA in aging, whereas the cell loss of the noradrenergic neurons in LC and subceruleus nuclei was evident. Considerable age-related dendritic alterations were observed in all catecholaminergic nuclei. In aging, the cross-sectional area decreased statistically and OD of the neurons in SN diminished with 13\%. In VTA, the neuronal 
cross-sectional area did not change its dimensions, while the OD increased with $19 \%$. In LC and subceruleus nuclei, the cross-sectional area decreased with $36 \%$ and the OD of the neurons decreased with $16 \%$. The most resistant to age-related changes catecholaminergic region in the rat is the VTA, followed by the pars compacta of $\mathrm{SN}$, while the rodent LC appears to be a very vulnerable region.

\section{REFERENCES}

1. Hassler R. Zur Pathologie der Paralysis agitans und des postencephalitischen Parkinsonismus. J Psychol Neurol 1938; 48: 387-476.

2. Mann DMA, Yates PO. Lipoprotein pigments - their relationship to ageing in the human nervous system. I. The lipofuscin content of nerve cells. Brain 1974; 97 : 481-488.

3. Mann DMA, Yates PO. Lipoprotein pigments - their relationship to ageing in the human nervous system. II. The melanin content of pigmented nerve cells. Brain 1974; 97 : 489-498.

4. Mann DMA. The locus coeruleus and its possible role in ageing and degenerative disease of the human central nervous system. Mech Ageing Dev 1983; 23: 73-94.

5. Marsden CD. Neuromelanin and Parkinson's disease. In: Birkmayer W, Duvoisin RC, editors. Extrapyramidal disorders. J Neural Transm 1983; Suppl 19: 121-142.

6. Brizzee KR, Neuron aging and neuron pathology. In: Johnson HA, editor. Relation between normal aging and disease. Aging, Raven Press, New York, 1985; 28: 191-223.

7. Gibb WRG, Mountjoy CQ, Mann DMA. The substantia nigra and ventral tegmental area in Alzheimer's disease and Down's syndrome. J Neurol Neurosurg Psychiat 1989; 52: $193-200$.

8. Usunoff KG. Cytoarchitectural, ultrastructural and histochemical characterization of substantia nigra. D Sci Med Dissertation, Medical Academy, Sofia; 1990.

9. Fearnley J, Lees A. Ageing and Parkinson's disease: substantia nigra regional selectivity. Brain 1991; 114: 2283-2301.

10. German DC, Manaye KF, White CL, III, Woodward DJ, McIntire DD, Smith WK et al. Disease-specific patterns of locus coeruleus cell loss. Ann Neurol 1992; 32: 667676.

11. Agid Y, Ruberg M, Javoy-Agid F, Hirsch E, Raisman-Vozari R, Vyas S et al. Are dopaminergic neurons selectively vulnerable to Parkinson's disease? In: Narabayashi H, Nagatsu T, Yanagisawa N, Mizuno Y, editors. Parkinson's disease: from basic research to treatment. Advances in Neurology. Raven Press, New York, 1993; 60: 158-164.

12. Finch CE. Neuroatrophy during aging: programmed or sporadic? Trends Neurosci 1993; 16: 104-110.

13. Herrero MT, Hirsch C, Kastner A, Luquin MR, Javoy-Agid F, Gonzalo LM et al. Neuromelanin accumulation with age in catecholaminergic neuron from Macaca fascicularis brainstem. Dev Neuroci 1993; 15: 37-48.

14. Kastner A, Hirsch E C, Herrero MT, Javoy-Agid F, Agid Y. Immunocytochemical quantification of tyrosine hydroxylase at a cellular level in the mesencephalon of control subjects and patients with Parkinson's and Alzheimer's disease. J Neurochem 1993; 61: 1024-1034.

15. Faraldi F, Reyes MG, Alfieri E, Levi AC. The aging substantia nigra: quantitative histologic study. Panminerva Med 1994; 36: 103-108.

16. Anglade P, Vyas S, Hirsch EC, Agid Y. Apoptosis in dopaminergic neurons of the human substantia nigra during normal aging. Histol Histopathol 1997; 12: 603610 .

17. Damier P, Hirsch EC, Agid Y, Graybiel AM. The substantia nigra of the human brain. II. Patterns of loss of dopaminecontaining neurons in Parkinson disease. Brain 199; 122: 1437-1448.

18. Siddiqi ZA, Peters A. The effect of aging on pars compacta of the substantia nigra in rhesus monkey. J Neuropathol Exp Neurol 1999; 58: 903-920.

19. Kordower JH, Emborg ME, Bloch J, Ma SY, Chu Y, Leventhal L et al. Neurodegeneration prevented by lentiviral vector delivery of GDNF in primate models of Parkinson's disease. Science 2000; 290: 769-773.

20. Cabello CR, Thune JJ, Pakkenberg H, Pakkenberg B. Ageing of substantia nigra in humans: cell loss may be compensated by hypertrophy. Neuropathol Appl Neurobiol 2002; 28: 283-293.

21. Itzev DE, Ovtscharoff WA, Marani E, Usunoff KG. Neuromelanin-containing, catecholaminergic neurons in the human brain: ontogenetic aspects, development and aging. Biomed Rev 2002; 13: 39-47.

22. Zecca L, Zucca FA, Wilms H, Sulzer D. Neuromelanin of the substantia nigra: a neuronal black hole with protective and toxic characteristics. Trends Neurosci 2003; 26: 578580 . 
23. Double KL, Halliday GM. New face of neuromelanin. $J$ Neural Transm 2006; Suppl 70: 119-23.

24. Kim ST, Choi JH, Kim D, Hwang O. Increases in TH immunoreactivity, neuromelanin and degeneration in the substantia nigra of middle aged mice. Neurosci Lett 2006; 396: 263-268.

25. Zucca FA, Bellei C, Gianelli S, Terreni MR, Gallorini M, Rizzio E et al. Neuromelanin and iron in human locus coeruleus and substantia nigra during aging: consequences for neuronal vulnerability. J Neural Transm 2006; 113: 757-767.

26. Attems J, Quass M, Jellinger KA. Tau and alpha-synuclein brainstem pathology in Alzheimer disease: relation with extrapyramidal signs. Acta Neuropathol (Berl) 2007; 113: 53-62.

27. Beach TG, Sue LI, Walker DG, Lue LF, Connor DJ, Caviness JN et al. Marked microglial reaction in normal aging human substantia nigra: correletaion with extraneuronal neuromelanin pigment deposits. Acta Neuropathol (Berl) 2007; 114: 419-424.

28. Chan CS, Guzman JN, Ilijc E, Mercer JN, Rick C, Tkatch T et al. "Rejuvenation" protects neurons in mouse models of Parkinson's disease. Nature 2007; 447: 1059-1060.

29. Kanaan NM, Kordower JH, Collier TJ. Age-related accumulation of Marinesco bodies and lipofuscin in rhesus monkey midbrain dopamine neurons: relevance to selective neuronal vulnerability. J Comp Neurol 2007; 502: 683-700.

30. Yamaguchi H, Shen J. Absence of dopaminergic neuronal degeneration and oxidative damage in aged DJ-1-deficient mice. Mol Neurodegener 2007; 2: 10.

31. Braak H, Braak E. Pathology of Alzheimer's disease. In: Calne DB, editor. Neurodegenerative diseases. WB Saunders Philadelphia 1994; 585-613.

32. Braak H, Braak E, Yilmazer D, de Vos RA, Jansen EN, Bohl J. Pattern of brain destruction in Parkinson's and Alzheimer's diseases. J Neural Transm 1996; 103: 455490.

33. Jellinger KA. Cell death mechanisms in Parkinson's disease. J Neural Transm 2000; 107: 1-29.

34. Usunoff KG, Itzev DE, Ovtscharoff WA, Marani E. Neuromelanin in the human brain. A review and atlas of pigmented cells in the substantia nigra. Arch Physiol Biochem 2002; 110: 257-369.

35. Stark AK, Pakkenberg B. Histological changes of the dopaminergic nigrostriatal system in aging. Cell Tissue Res 2004; 318: 81-92.

36. Tatton WG, Greenwood CE, Salo PT, Seniuk NA. Transmitter synthesis increases in substantia nigra neurons of the aged mouse. Neurosci Lett 1991; 131: 179-182.

37. Emerich DF, McDermott P, Krueger P, Banks M, Zhao J, Marszalkowski J et al. Locomotion of aged rats: relationship to neurochemical but not morphological changes in nigrostriatal dopaminergic neurons. Brain Res Bull 1993; 32: 477-486.

38. Schuligoi R, Fernandez J, Heavens RP, Sirinathsinghji DJ. Decreased tyrosine hydroxylase mRNA but not cholecystokinin mRNA in the pars compacta of the substantia nigra and ventral tegmental area of aged rats. Mol Brain Res 1993; 19: 333-338.

39. Irwin I, DeLanney LE, McNeill T, Chan P, Forno LS, Murphy GM Jr et al. Aging and the nigrostriatal dopamine system: a non-human primate study. Neurodegeneration 1994; 3: 251-265.

40. Bannon ML, Whitty CJ. Age-related and regional differences in dopamine transporter mRNA expression in human midbrain. Neurology 1997; 48: 969-977.

41. Kubis N, Faucheux BA, Ransmayr G, Damier P, Duyckaerts C, Henin D et al. Preservation of midbrain catecholaminergic neurons in very old human subjects. Brain 2000; 123: 366-373.

42. Uchida K, Kihara N, Hashimoto K, Nakayama H, Yamaguchi R, Tateyama S. Age-related histological changes in the canine substantia nigra. J Vet Med Sci 2003; 65: 179-185.

43. McCormack AL, Di Monte DA, Delfani K, Irwin I, DeLanney LE, Langston WJ et al. Aging of the nigrostriatal system in the squirrel monkey. J Comp Neurol 2004; 471: 387-395.

44. Tatton WG, Greenwood CE, Verrier MC, Holland DP, Kwan MM, Biddle FE. Different rates of age-related loss for four murine monoaminergic neuronal populations. Neurobiol Aging 1991; 12: 543-556.

45. De La Cruz CP, Revilla E, Venero GL, Ayala A, Cano J, Machado A. Oxidative inactivation of tyrosine hydroxylase in substantia nigra of aged rat. Free Radic Biol Med 1996; 20: 53-61.

46. Collier TJ, Lipton J, Daley BF, Palfi S, Chu Y, Sortwell C et al. Aging-related changes in the nigrostriatal dopamine system and the response to MPTP in nonhuman primates: 
diminished compensatory mechanisms as a prelude to parkinsonism. Neurobiol Dis 2007; 26: 56-65.

47. Himi T, Cao MH, Mori N. Reduced expression of the molecular markers of dopaminergic neuronal atrophy in the aging rat brain. J Gerontol 1995; 50: 193-200.

48. McNeill TH, Koek LL, Haycock JW. The nigrostriatal system and aging. Peptides 1984; 5 Suppl 1: 263-268.

49. McNeill TH, Koek LL, Haycock JW. Age-correlated changes in dopaminergic nigrostriatal perikarya of the C57BL/6NNia mouse. Mech Ageing Dev 1984; 24: 293307.

50. McNeill TH, Koek LL. Differential effects of advancing age on neurotransmitter cell loss in the substantia nigra and striatum of C57BL/6N mice. Brain Res 1990; 521: 107-117.

51. Greenwood CE, Tatton WG, Seniuk NA, Bidle FG. Increased dopamine synthesis in aging substantia nigra neurons. Neurobiol Aging 1991; 12: 557-565.

52. Pakkenberg H, Andersen BB, Burns RS, Pakkenberg B. A stereological study of substantia nigra in young and old rhesus monkeys. Brain Res 1995; 693: 201-206.

53. Vijayshankar N, Brody HA. A quantitative study of the pigmented neurons in the nuclei locus coeruleus and subcoeruleus in man as related to aging. $J$ Neuropathol Exp Neurol 1979; 38: 490-496.

54. Wree A, Braak H, Schleicher A, Zilles K. Biomathematical analysis of the neuronal loss in the aging human brain of both sexes, demonstrated in pigment preparations of the pars cerebellaris loci coerulei. Anat Embryol 1980; 160: 105-119.

55. Marcyniuk L, Mann DMA, Yates PO. The topography of nerve cell loss from the locus caeruleus in elderly persons. Neurobiol Aging 1989; 10: 5-9.

56. Manaye KF, McIntire DD, Mann DMA, German DC. Locus coeruleus cell loss in the aging human brain: A non-random process. J Comp Neurol 1995; 358: 79-87.

57. Baker KG, Tork I, Hornung JP, Halasz P. The human locus coeruleus complex: an immunohistochemical and three dimensional reconstruction study. Exp Brain Res 1989; 77: 257-270.

58. Chan-Palay V, Asan E. Quantitation of catecholamnine neurons in the locus coeruleus in human brains of normal young and old adults and in depression. J Comp Neurol 1989; 287: 357-372.

59. Chan-Palay V, Asan E. Alterations in the catecholamine neurons of the locus coeruleus in senile dementia of the Alzheimer type and in Parkinson's disease with and without dementia and depression. J Comp Neurol 1989; 287: 373-392.

60. Iversen LL, Rossor MN, Reynolds GP, Hills R, Roth M, Mountjoy CQ et al. Loss of pigmented dopamine-betahydroxylase positive cells from locus coeruleus in senile dementia of Alzheimer type. Neurosci Lett 1983; 39: 95 100 .

61. Itzev D, Usunoff KG, Marani E, Ovtscharoff W. Age-related changes in the tyrosine hydroxylase immunoreactive neurons in rat mesencephalon. C R Acad Bulg Sci 2006; 59: 337-342.

62. Vacca LL, Abrahams SJ, Naftchi NE. A modified peroxidase-antiperoxidase procedure for improved localization of tissue antigens: localization of substance $P$ in rat spinal cord. J Histochem Cytochem 1980; 28: 297-307.

63. Paxinos G, Watson C. The Rat Brain in Stereotaxic Coordinates, Fourth edition. Academic Press, San Diego 1998.

64. German DC, Manaye KF, Smith WK, Woodward DJ, Saper CB. Midbrain dopaminergic cell loss in Parkinson's disease: computer visualization. Ann Neurol 1989; 26: 507-514.

65. Gibb WRG, Lees AJ. Pathological clues to the cause of Parkinson's disease. In: Marsden CD, Fahn S, editors. Movement Disorders 3. Butterworth Heinemann, Oxford, 1994; 147-166.

66. Ma SY, Roytt M, Collan Y, Rinne JO. Unbiased morphological measurements show loss of pigmented nigral neurons with ageing. Neuropathol Appl Neurobiol 1999; 25: 394-399.

67. Ma SY, Ciliax BJ, Stebbins G, Jaffar S, Joyce JN, Cochran EJ et al. Dopamine-transporter-immunoreactive neurons decrease with age in the human substantia nigra. J Comp Neurol 1999; 409: 25-37.

68. Chu Y, Kompoliti K, Cochran EJ, Mufson EJ, Kordower $\mathrm{JH}$. Age-related decreases in Nurr1 immunoreactivity in the human substantia nigra. J Comp Neurol 2002; 450: 203-214.

69. Siddiqi Z, Kemper TL, Killiany R. Age-related neuronal loss from the substantia nigra-pars compacta and ventral tegmental area of the rhesus monkey. J Neuropathol Exp Neurol 1999; 58: 959-971.

70. Gerhardt GA, Cass WA, Yi A, Zhang Z, Gash DM. 
Changes in somatodendritic but not terminal dopamine regulation in aged rhesus monkey. $J$ Neurochem 2002; 80: 168-177.

71. Ishida Y, Okawa Y, Ito S, Shirokawa T, Isobe K. Agedependent changes in dopaminergic projections from the substantia nigra pars compacta to the neostriatum. Neurosci Lett 2007; 418: 257-261.

72. Cruz-Muros I, Afonso-Oramas D, Abren P, Barroso-Chinea P, Rodriguez M, Gonzalez MC et al. Aging of the rat mesostriatal system: differences between the nigrostriatal and the mesolimbic compartments. Exp Neurol 2007; 204: 147-161.

73. Mouton PR, Pakkenberg B, Gundersen HJ, Price DL. Absolute number and size of pigmented locus coeruleus neurons in young and aged individuals. J Chem Neuroanat 1994; 7: 185-190.

74. Grudzien A, Shaw P, Weintraub S, Bigio E, Mash DC, Mesulam MM. Locus coeruleus neurofibrillary degeneration in aging, mild cognitive impairment and early Alzheimer's disease. Neurobiol Aging 2007; 28: 327-335.

75. Rommelfanger KS, Weinshenker D. Norepinephrine: the redheaded stepchild of Parkinson's disease. Biochem Pharmacol 2007; 74: 177-190.

76. Goldman G, Coleman PD. Neuron numbers in locus coeru- leus do not change with age in Fisher 344 rat. Neurobiol Aging 1981; 2: 33-36.

77. Sturrock RR, Rao KA. A quantitative histological study of neuronal loss from the locus coeruleus of ageing mice. Neuropathol Appl Neurobiol 1985; 11: 55-60.

78. Shores MM, White SS, Veith RC, Szot P. Tyrosine hydroxylase mRNA is increased in old age and norepinephrine uptake transporter mRNA is decreased in middle age in locus coeruleus of Brown-Norway rats. Brain Res 1999; 826: 143-147.

79. Cruz-Sanchez FF, Cardozo A, Castejon C, Tolosa E, Rossi ML. Aging and the nigro-striatal pathway. J Neural Transm 1997; 51: 9-25.

80. Lolova IS, Lolov SR, Itzev DE. Aging and dendritic morphology of the rat laterodorsal and pedunculopontine tegmental nuclei. Mech Ageing Dev 1997; 97: 193-205.

81. Lolova IS, Lolov SR, Itzev DE, Usunoff KG. Age-related changes in the NADPH-diaphorase-positive dendrites in the dorsolateral neuronal column of the periaqueductal gray in rat. Mech Ageing Dev 2000; 120: 77-86.

82. Von Bohlen und Halbach O, Zacher C, Gass P, Unsicker K. 2006. Age-related alterations in hippocampal spines and deficiencies in spatial memory in mice. $J$ Neurosci Res 2006; 83: 525-531. 